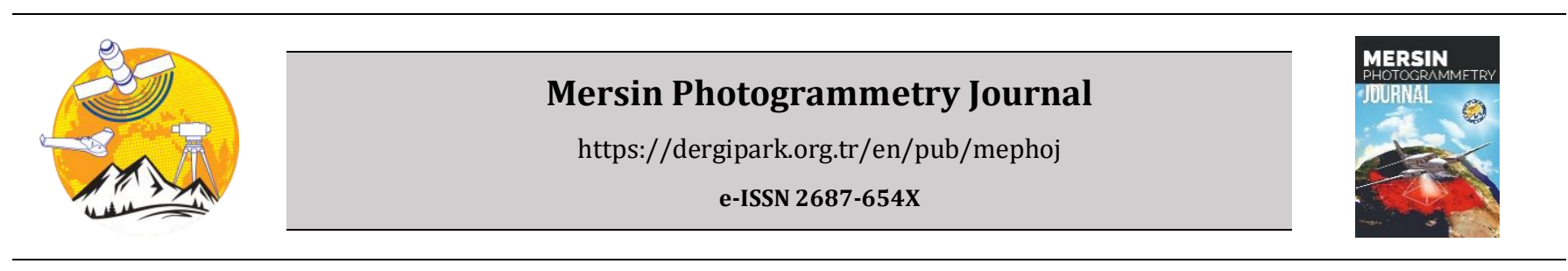

\title{
Documenting historic tileworks using smartphone-based photogrammetry
}

\author{
Ali Asadpour *1 (1) \\ ${ }^{1}$ Shiraz University of Arts, Faculty of Architecture \& Urbanism, Department of Interior Architecture, Shiraz, Iran
}

Keywords

Smartphone

Documentation

Photogrammetry

Tile paintings

Hāfez tomb

\begin{abstract}
Photogrammetry is a metric technique for indirect measurement through images. This technique could be applied in recording architectural features and documenting buildings. Therefore, smartphone-based photogrammetry can be considered a creative method for architects and conservators to document monuments quickly and promptly. The main objective of this paper is to study the smartphone-based photogrammetry capabilities in two case studies in terms of accuracy and precision. Historic tileworks in Hāfez tomb, Shiraz, Iran, has been considered as examples of traditional decorations in Iranian architecture. For this purpose, close-range photogrammetry with stereo photography was used. A smartphone camera has captured the photos. Photogrammetric steps were performed in Agisoft Metashape Professional. The result was 3D models and an orthoimage of the tiles. The accuracy of the results was acceptable for ordinary documentation and differed on average $0.45 \%$ to as-built measures. Orthoimage is believed to be an important document for analyzing and studying the patterns and colors used in these works of art. The results of this study emphasized that closerange photogrammetry with a smartphone can in the future be a public and reliable technique for documenting architectural heritages, especially in medium and small-scale projects.
\end{abstract}

\section{INTRODUCTION}

Documentation is defined as a systematic collecting and archiving activity to prepare historic building records (Stylianidis, 2020). However, it is a costly and time-consuming procedure, particularly in documenting architectural ornaments and interior decorations. Much of these architectural heritages have been disappeared at a higher rate than that which could be well documented in the last decades by the rapid reconstruction or renovation policies. Hence, developing a cheap and easy technique for documentation is necessary. Recording all of these works is difficult and perhaps impossible. Since digital cameras are one of the practical and relatively inexpensive devices for documentation, photogrammetry would be an affordable, instantaneous, and accessible technique to record architectural evidence and documenting as-is features and building properties.

The idea of Single Images in Conservation recommended by International Committee for Architectural Photogrammetry, CIPA, also presupposes the importance of images in the conservation of architectural heritages (see Schuhr \& Kanngieser,

* Corresponding Author

*(asadpour@shirazartu.ac.ir) ORCID ID 0000-0002-6837-0804
1999, 2003). CIPA's general mission also emphasizes the development of principles and practices for recording, documenting, and managing information by specialized tools and techniques (Quintero et al., 2017). It seems that photogrammetry could be a cost-effective method in the future. That means it could be more pervasive than it is today.

Since photogrammetry is a 3D measuring technique through a central projection model, it should be considered as a multidimensional discipline that integrates art, science, and technology. The primary purpose of a photogrammetric measurement is the three-dimensional reconstruction of an object, which can be re-accessed at any time. Another purpose is producing an orthoimage that can be used for real distance measuring, which is being done on maps with the consideration of scale factor since it is adjusted properly for elevation, lens distortion, and camera tilt (Luhmann, Robson, Kyle, \& Harley, 2011; Stylianidis, 2020). These features make photogrammetry attractive for experts in the fields of architecture, conservation, archeology, and documenting cultural heritage. In this context, architectural photogrammetry can pave the way for accurate documentation and could be rapidly widespread by the growth of mobile Cite this article

Asadpour A (2021). Documenting historic tileworks using smartphone-based photogrammetry. Mersin Photogrammetry Journal, 3(1), 15-20 
digital camera technology and by the development of photogrammetry applications.

The main objective of this study is to present the accuracy, precision, and ability of a smartphone for architecture photogrammetry. Therefore, a set of tiles, which cannot be easily well documented with ordinary photography due to their dimensions and position, was selected for this survey. These tiles have historical value and should be considered a masterpiece. In the following, the steps of capturing, data processing, generating the final 3D model, and orthoimage production has been described.

\section{LITERATURE REVIEW}

There are not many published articles about smartphone-based photogrammetry. Available researches could be divided into two categories: The first group is papers that aim to measure the accuracy of smartphone cameras for photogrammetry purposes. The second category is papers that have used smartphone-based photogrammetry for architectural documentation.

Ebrahim (2004) evaluated the use and accuracy of two digital built-in mobile phone cameras in a laboratory and a field test. His results were promising in terms of using smartphone cameras to a certain estimated accuracy of $1 / 400$. The photo resolution of his mobile phone was 640 by 480 pixels. For this reason, he attributed the poor accuracy of mobile cameras to their lack of resolution. Gruen and Akca (2007) calibrated various mobile phones over indoor tests using self-calibration. Despite some diagnosed substantial systematic errors, they stated that if handle properly, these devices could give us a very interesting option doing smartphone-based photogrammetry in terms of accuracy, costs, and flexibility. Takahashi and Chikatsu (2009) conducted the calibration of indoor and outdoor target tests for seventeen smartphones with 10-megapixel cameras. They concluded that mobile phone cameras can take the place of consumergrade digital cameras. In 2011, Sarhan Satchet compared the mobile cameras with digital cameras in twenty-four targeted test fields; he suggested that whenever mobile camera resolution increases the Root Mean Square Error dwindle. It should not be forgotten that all these mobile phones tested so far had a resolution of 5 to 10 megapixels. One of the most recent studies compared the Nikon D310 camera with two Samsung phones (Note III \& S5) and a Sony phone (Xperia Z2) offering 20.7, 16, and 13-megapixel images, respectively. The results of this comparison showed that mobile cameras are efficient, fast, and useful, and their accuracy for close-range photogrammetry is such that it offers good results compared to high-quality cameras. As the quality of the images increases, the desired features in the photogrammetry also improve (Fawzy, 2015).

The effect of the mobile camera quality on improving the accuracy and precision of photogrammetric work in a study by El-Ashmawy (2017) at a university in Cairo has been measured. He tested two 5 and 20-megapixel cameras from one brand. The results showed that higher resolution leads to more accurate results, and in general mobile cameras are suitable for close-range photogrammetry in terms of accuracy, cost, and flexibility. Quite similar results were obtained in 2019 with the test of 5, 8, and 20-megapixel mobile phones revealing that the measurement accuracy in all directions differed only 0.4 to $0.5 \mathrm{~mm}$, which is equivalent to less than half of a pixel (Shatnawi \& Obaidat, 2019). In general, these studies show that the higher the resolution of mobile cameras, the better the accuracy of photogrammetry.

Unfortunately, there are very few articles in the field of architectural smartphone photogrammetry. For instance, by a 3D survey of a student design courses model, Hernán-Pérez, Domínguez, González, and Martín (2013) estimated the accuracy of an iPhone based close-range photogrammetry around one centimeter. The findings of the present study could be considered as part of these efforts to develop the use of mobile phones in architectural photogrammetry and documentation of historical monuments.

\section{STUDY AREA}

The tiles studied in this paper are a part of the Hāfez tomb facade, one of the famous Iranian poets of the 14th century, in Shiraz, Iran (Figure 1). Khwāja Shams-ud-Dīn Muḥammad Hăfez-e Shīrāzī (13151390) lived in Shiraz during Timurid Empire (13701507) and died in this city at the age of 74 or 75 . Numerous buildings have been established on his grave at different times throughout history, but Karīm Khān-e Zand (1705-1779), founder of the Zand dynasty, built the most significant of them. He installed a marble stone on Hāfez grave, established a portico with four columns in front of it, and formed a garden around the tomb in 1772-73, which became the basis for the later developments.

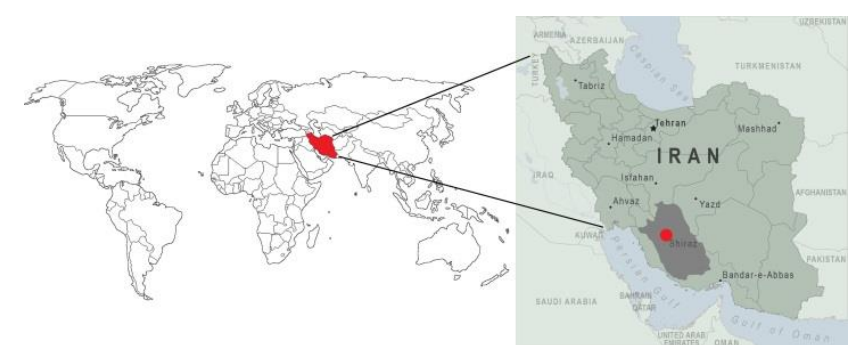

Figure 1. Shiraz location-Fars province/IRAN

In the twentieth century, a French architect and archaeologist, André Godard (1881-1965) was invited to renovate the tomb. Godard developed the Karìm Khān layout, presented a new design, installed a dome with eight columns on the grave and, widened the porch of the Karīm Khān to twenty columns. Designing started in 1936 and the building almost completed in 1938. The tiles of the southern facade of the porch on both the east and west sides are the work of the famous painter of Shiraz, Seyyed Sadr al-Dīn-Shayesteh, and the implementation and installation was done by the famous tile worker of that time, Karim Faghfouri.

This study examined these two 82-year-old tile works on the west and east sides of the central porch 
using a smartphone-based photogrammetry procedure. These two tiles are not only located on both sides of the porch but also are symmetrical in design and layout. Figure 2 shows western and eastern tiles. The dimensions of the outer rectangular frame of the western tiles were equal to 2.98 by 4.96 meters. The final height of it is 4.96 meters. The tiles are installed at a height of about 1.50 meters above the pathway. The dimensions of the outer rectangular frame of the eastern tiles were equal to 2.99 by 4.98 meters. The final height of it is 4.98 meters. The location and the height of these tiles make taking flat photos difficult.

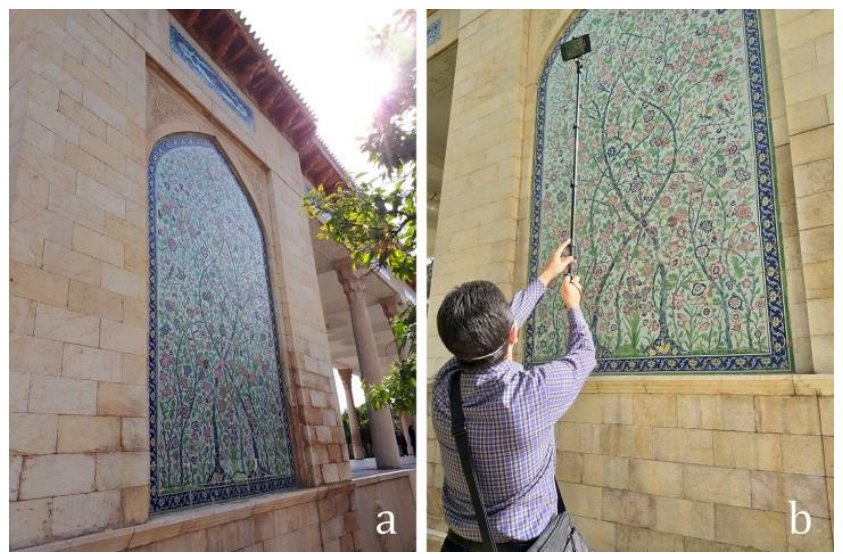

Figure 2. Tiles of the western (a) and eastern parts (b) of the porch in Hāfez Tomb

\section{METHOD}

A Samsung Galaxy A720F/DS (16 MP, f/1.9, and 27 $\mathrm{mm}$ ) is used for capturing images (Figure 3). All photos were taken with a single camera. To have the highest quality, images were taken in $4608 \times 3456$ pixels. On a sunny day in March 2021, shooting was started based on the stereographic principle. The location of the shooting had certain limitations that were part of the study; the pathway in front of the tiles was narrow (about 2 meters) and the trees were an important obstacle for shooting from different distances and stations. For photography, a $1.25 \mathrm{~cm}$ long monopod equipped with Bluetooth was used.

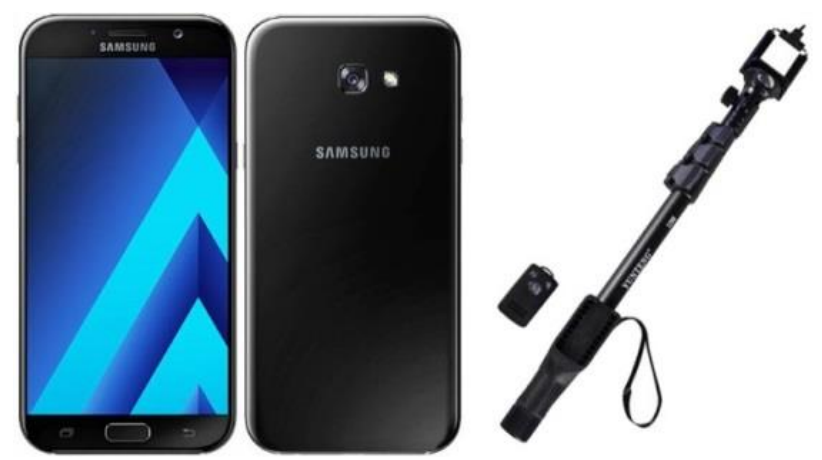

Figure 3. Samsung Galaxy A720F and a monopod

An ordinary laser distance meter device on site measured the length and width of these tiles and their outer rectangular stone frame. This device is equipped with a laser grade II, type $635 \mathrm{~nm}$ with $\pm 3 \mathrm{~mm}$ accuracy. To ensure the accuracy of the measurements, each distance was measured three times and the value with the highest frequency was used.

This study is based on target-free photogrammetry and its purpose is to show the efficiency and accuracy of smartphone photogrammetry for architectural documentation. However, five checkpoints in each case study were used to assess the accuracy of the orthoimages and scaling the results. These checkpoints are so distributed that they could be identified in both orthoimages and 3D models. Table 1 shows the position of these checkpoints on the facade. Points 1, 2, and 3 are on one plane, and points 4 and 5 are on another plane. Photography started from point 1 and the camera moved in a vertical direction upwards. The same work is done for other parts of the tiles.

Table 1. Five checkpoints distributed on the façade with relevant distances measured on-site

\begin{tabular}{llll}
\hline Legend & East Tiles (m) & West Tiles (m) \\
\hline & & $\begin{array}{l}\text { Stone width } \\
\mathrm{a}=2.984\end{array}$ & $\begin{array}{l}\text { Stone width } \\
\mathrm{a}=2.992\end{array}$ \\
& $\begin{array}{l}\text { Stone length } \\
\mathrm{b}=4.960\end{array}$ & $\begin{array}{l}\text { Stone length } \\
\mathrm{b}=4.983\end{array}$ \\
& $\begin{array}{l}\text { Tileworks length } \\
\mathrm{c}=4.706\end{array}$ & $\begin{array}{l}\text { Tileworks length } \\
\mathrm{c}=4.705\end{array}$ \\
\hline
\end{tabular}

The Agisoft Metashape Professional (2019), as stand-alone automatic lens calibration software, was used for this close-range photogrammetry. The workflow consists of seven consecutive steps:

1- Loading photos into Metashape,

2- Inspecting loaded images, removing unnecessary ones,

3- Aligning photos,

4- Building dense point cloud,

5- Building mesh or 3D polygonal model, 6- generating texture, and

7- Exporting results

Orthoimages were entered in AutoCAD and scaled or checked using on-site measured checkpoints.

\section{RESULTS AND DISCUSSION}

Eighty-four camera stations (photos) have been used in this project; 39 camera stations for west tiles and 45 stations for east tiles. Because of using a monopod, many of the photos were captured in parallel with the tile works. Due to the height of the tilework and the small distance in front of it, some photos were taken unparalleled. However, efforts were made to avoid oblique photography as much as possible (Figure 4). All photos loaded into the Agisoft Metashape Professional version and aligned successfully. Camera calibrations are reported in Table 2, and image residuals are represented in Figure 5. 

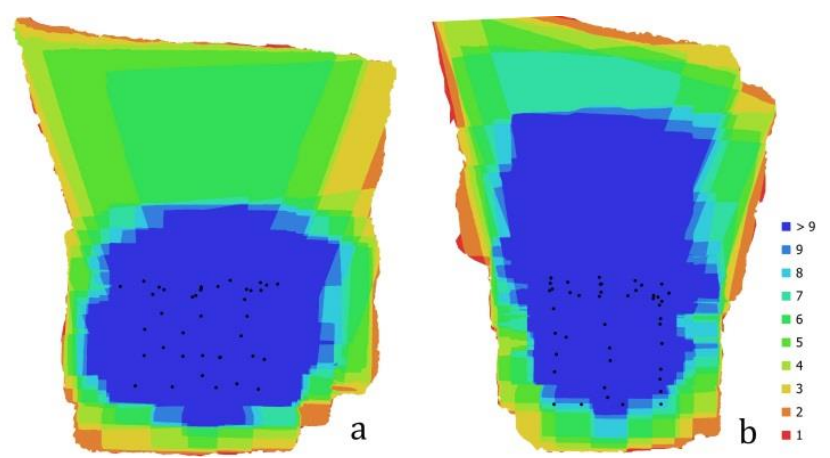

Figure 4. Camera locations and image overlap in West tilework (a) and East tilework (b)

The Samsung Galaxy A720F/DS has a 16megapixel camera with $\mathrm{f} / 1.9$ and a $27 \mathrm{~mm}$ lens. Thus, a wide range of a scene must be projected on a very small area of the camera sensor. As a result, averaged residuals are not homogenous across the entire surface of the sensor. The wave effect in the error distribution is seen in the image residuals. In the center and peripheral circles, the size of these errors is about 2 pixels, which here equals $2 \mu \mathrm{m}$ (each pixel was calculated $1 \mu \mathrm{m}$ in the Agisoft Metashape report). There are more errors in the four corners, especially in the right corners. The wide-angle mobile lens may have exacerbated the errors in the corners. However, the errors are orderly. This concentric distribution of image residuals may be revealing that residuals come from a limited polynomic model. In an inaccurate calibration, these concentric residuals are less conspicuous because, in areas where the projective model does not match the actual behavior of light paths, residuals are much larger (Sanz-Ablanedo, Chandler, Rodríguez-Pérez, \& Ordóñez, 2018, p. 8). However, this issue needs more laboratory and field studies.

Table 2. Camera calibration report, Agisoft Metashape

\begin{tabular}{|c|c|c|c|c|}
\hline \multirow{5}{*}{$\frac{\mathscr{d}}{=}$} & Items & value & Items & value \\
\hline & $\mathrm{F}$ & $3659.42(\mu \mathrm{m})$ & $\mathrm{k} 2$ & -0.595658 \\
\hline & $\mathrm{cx}$ & $-8.83916(\mu \mathrm{m})$ & k3 & 0.667333 \\
\hline & cy & $37.4567(\mu \mathrm{m})$ & $\mathrm{p} 1$ & -0.000264763 \\
\hline & $\mathrm{k} 1$ & 0.177442 & $\mathrm{p} 2$ & -0.00105576 \\
\hline \multirow{4}{*}{ 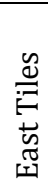 } & $\mathrm{F}$ & $3714.69458(\mu \mathrm{m})$ & $\mathrm{k} 2$ & -0.647948 \\
\hline & $\mathrm{cX}$ & $7.11677(\mu \mathrm{m})$ & $\mathrm{k} 3$ & 0.755168 \\
\hline & cy & $38.2493(\mu \mathrm{m})$ & $\mathrm{p} 1$ & -0.000942678 \\
\hline & $\mathrm{k} 1$ & 0.184452 & p2 & 0.000287152 \\
\hline
\end{tabular}
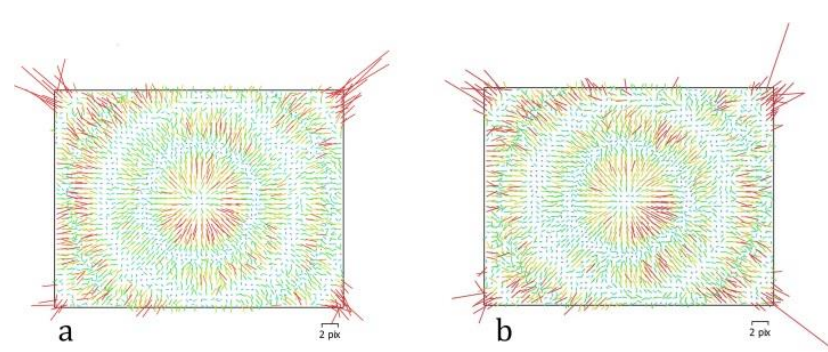

Figure 5. Image residuals for Samsung A720F, West tiles (a) and East tiles (b), Agisoft Metashape Professional report
Building a dense point cloud was the next step in the photogrammetry process (Figure 6). Similarly, the other steps (building mesh and generating texture) were also completed successfully. In the final stage, a threedimensional model of the tileworks was obtained. This model on the digital platform is exported into 2D orthoimage for further detail drawings. Thanks to the checkpoints measured before, it was possible to scale this 2D image in AutoCAD. To do this, the largest distance measured (parameter (b) according to Table 1) was considered as the basis for scaling. This value was $4.960 \mathrm{~m}$ and $4.983 \mathrm{~m}$ for west and east tilework, respectively. As the corners of a stone frame act as checkpoints 2 and 3, these points could be seen well in the orthoimages. Thanks to the accuracy of drawing in AutoCAD, other data could be obtained easily (Figures 7 and 8).

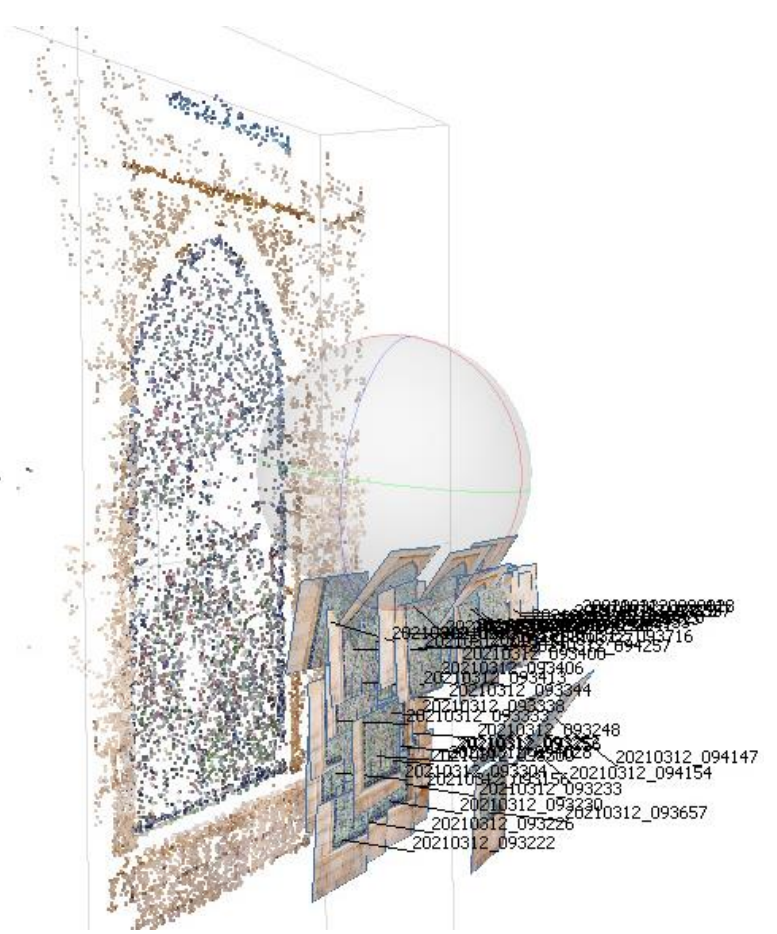

Figure 6. Building point cloud in Agisoft Metashape Professional for west tiles

Comparing the actual sizes with what was measured in the orthoimage shows some differences (Table 3). The maximum difference in dimensions is less than $0.029 \mathrm{~m}$, which is equal to less than $1 \%$ and the minimum is equal to $0.006 \mathrm{~m}$, which is more than $0.1 \%$. In general, it can be said that the average difference in size is equal to $0.45 \%$. Therefore, it could be concluded that the accuracy of the orthoimages is acceptable for architectural ordinary documentation purposes. In addition to the technical structure of the camera and mobile lens, this difference could be due to the low accuracy of the laser distance meter device and the lack of a pre-mounted target on the wall. Accurate detection of checkpoints on the image is associated with errors that can also be effective in the result. To correct this problem, for example, it is possible to install recognizable and measurable targets in place and measure their distances. This job does require more specialized knowledge and skills. 


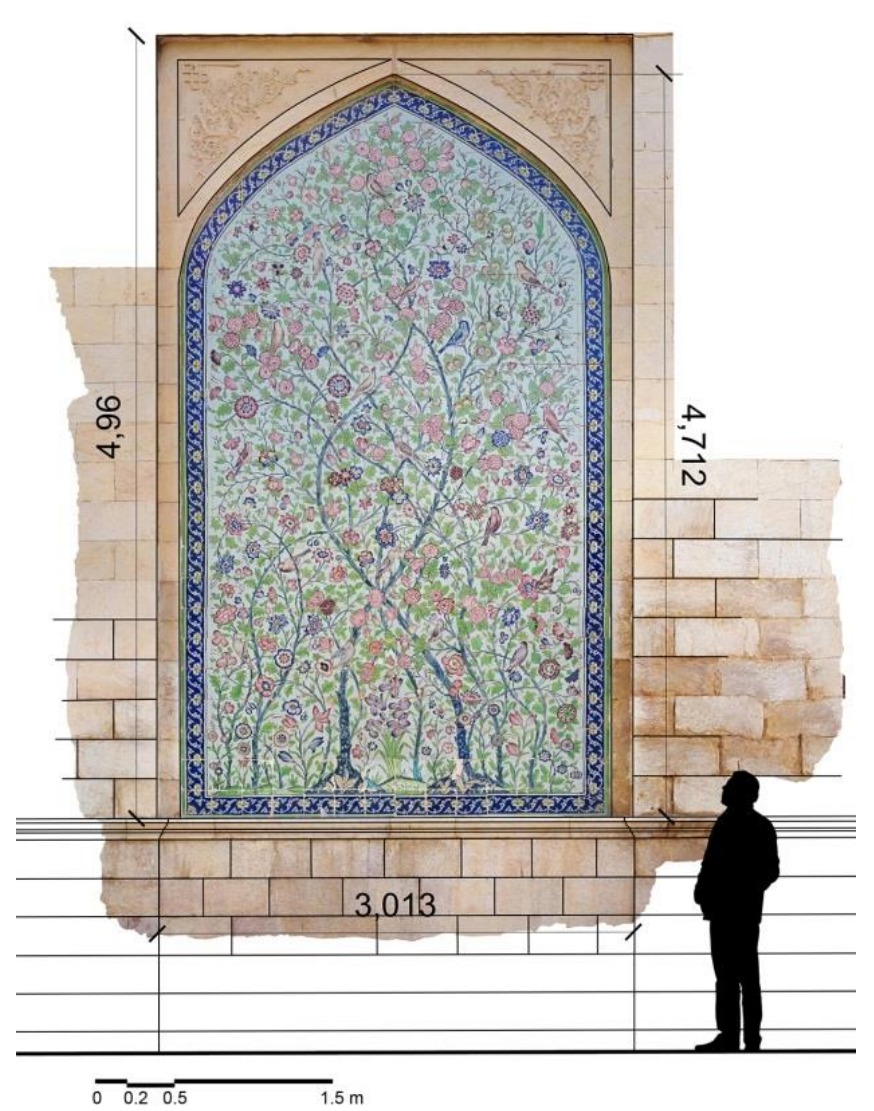

Figure 7. Drawing on the final metric orthoimage of west tilework in AutoCAD

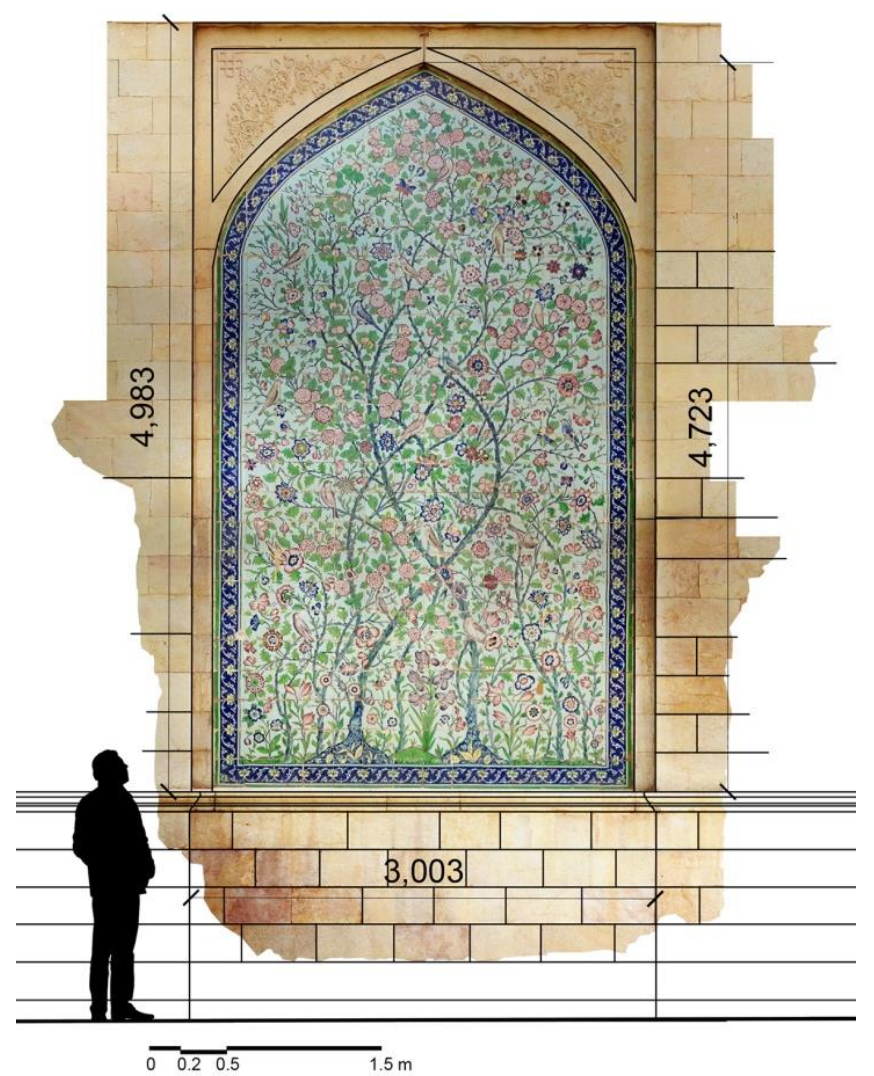

Figure 8. Drawing on the final metric orthoimage of east tilework in AutoCAD

Now that the accuracy and validity of the photogrammetry method and orthoimage production have been confirmed, a final flat image of the west tilework can be obtained (Figure 8). No significant distortion was seen in the orthoimage. Only in the upper section near the arc lines, a slight distortion exists, which may be caused by oblique photography. These distortions had no significant effect on the final quality and visual content of the tiles. The number of photos taken from the top third of the tilework is less than the other sections; maybe having more photos from this part could have reduced or eliminated these distortions in final orthoimage.

Table 3. On-site dimensions and those extracted from orthoimages

\begin{tabular}{|c|c|c|c|c|}
\hline & Items & $\begin{array}{l}\text { On- } \\
\text { site } \\
\text { (m) } \\
\end{array}$ & $\begin{array}{l}\text { Orthoimage } \\
\text { (m) }\end{array}$ & $\begin{array}{l}\text { Differ } \\
\text { ence } \\
(\%) \\
\end{array}$ \\
\hline \multirow{3}{*}{$\vec{u}_{\vec{s}}^{\vec{s}}$} & Stone width (a) & 2.984 & 3.013 & 0.97 \\
\hline & Stone length (b) & 4.960 & 4.960 & 0 \\
\hline & Tileworks length (c) & 4.706 & 4.712 & 0.12 \\
\hline \multirow{3}{*}{$\ddot{\tilde{w}}$} & Stone width (a) & 2.992 & 3.003 & 0.36 \\
\hline & Stone length (b) & 4.983 & 4.983 & 0 \\
\hline & Tileworks length (c) & 4.705 & 4.723 & 0.38 \\
\hline
\end{tabular}

Despite all this, the final orthoimage contains the characteristic features of the 82-year-old historical ornaments and records it's actual as-is details. In response to the urgent need of restorers and designers to have exact detailed information, these images could be an important source for conservation, restoration, and repair programs in the future. These digital data can also be used for different types of research in terms of aesthetics, design styles, composition patterns, and the like for those interested in art subjects.

\section{CONCLUSION}

Documenting monuments and recording buildings ornaments are an essential and even indispensable obligation for all countries, but it can also be very timeconsuming and costly. In a country like Iran with an ancient history and diverse cultural heritage, this cannot be done by government or local institutions alone. Universities and NGOs must play an important role in this regard. That is why it is necessary to find cheap and accurate ways and methods for architectural documentation work requiring expertise with cheap and limited equipment.

Today, the mobile phone has become an ordinary and multifunctional device, a cheap and user-friendly tool. Smartphone-based photogrammetry can therefore be an efficient technique for architectural documentation. Working with a smartphone is easier than working with many photogrammetric cameras. It seems smartphone-based photogrammetry has the potential to be further developed in the future. The only challenge is the results accuracy and the degree of its precision.

Smartphone-based photogrammetry can also be considered as part of emergency photogrammetry. In an earthquake-prone country like Iran, where most monuments are made of clay and brick, working with a mobile camera can be an alternative to expensive cameras for small projects. This method can be a quick way with specialized knowledge that can be easily transferred to students or other interested parties. 


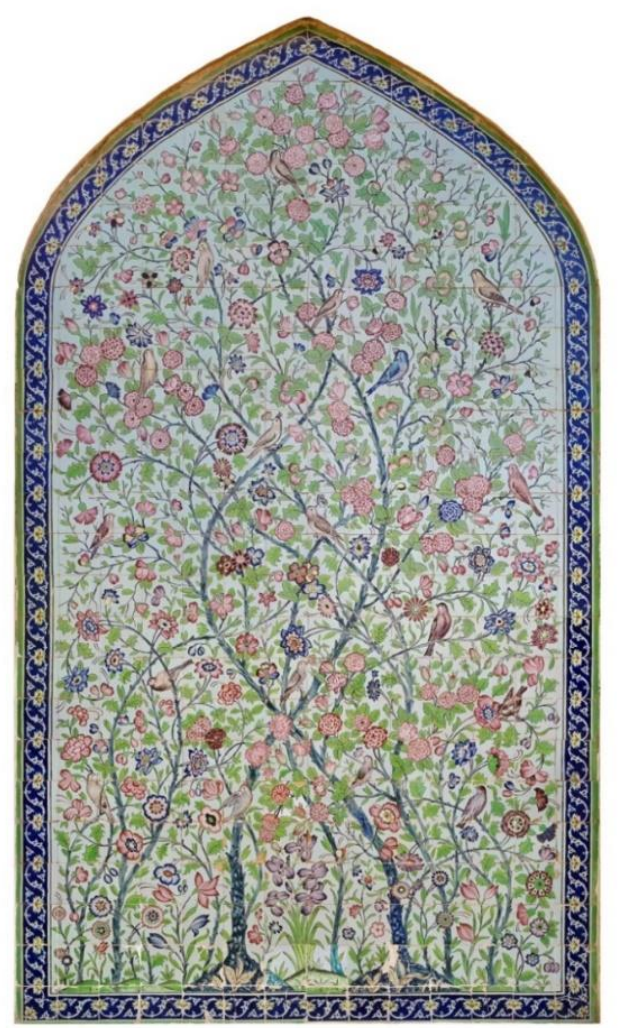

Figure 8. Final orthoimage production of the west tilework

The smartphone-based photogrammetry method is successfully applied in this study. The procedure reliability in terms of accuracy and precision shows acceptable results. On average, about $0.45 \%$ discrepancy was calculated in the orthoimage and asbuilt dimensions measured by laser distance meter. Besides, no significant distortions were observed in the main part of the tileworks. Stereo pair photos, parallel and high-resolution photography can enhance the results. Using mobile phones with higher quality photography and targeting checkpoints in place can increase the accuracy of the work. Laboratory and field studies can further reveal the impact of these suggestions.

The 3D model and the orthoimage obtained from this study are considered part of the digital archive of exquisite tileworks in thăfez tomb, which can be a document and a source for future studies and indirect measurements. The complex layout, colorful design, and diverse elements of these tileworks could not be documented by any conventional or primitive methods. Simple photography could not be useful due to the size of the tiles and their position. Therefore, smartphonebased photogrammetry was a cheap, fast, reliable, and accurate way for our purpose. Further studies could focus on photogrammetry of architectural decorations on curved surfaces or non-flat ornaments like capitals, domes, and the like. The discrepancy between different types of mobile cameras with different brands and resolutions may also be the subject of other researches in smartphone-based photogrammetry.

\section{Conflicts of interest:}

The authors declare no conflicts of interest.

\section{REFERENCES}

Ebrahim M (2004). Using Mobile Phone Digital Cameras in Digital Close Range Photogrammetry. The Photogrammetric Journal of Finland, 19(1), 1122.

El-Ashmawy K L A (2017). Using smart phones for deformations measurements of structures. Geodesy and Cartography, 43(2), 66-72. doi:10.3846/20296991.2017.1330770

Fawzy H E-D (2015). The accuracy of mobile phone camera instead of high resolution camera in digital close range photogrammetry. International Journal of Civil Engineering and Technology, 6(1), 76-85.

Gruen A \& Akca D (2007). Mobile Photogrammetry. Paper presented at the Dreiländertagung SGPBF, DGPF und OVG, ,, Muttenz, Switzerland.

Hernán-Pérez A S, Domínguez M G, González C R \& Martín A P (2013). Using IPhone Camera in Photomodeler for the 3D Survey of a Sculpture as Practice for Architecture's Students. Procedia Computer Science, 25, 345-347. doi:https://doi.org/10.1016/j.procs.2013.11.041

Luhmann T, Robson S, Kyle S \& Harley I A (2011). Close Range Photogrammetry: Principles, Techniques and Applications. Scotland, UK: Whittles Publishing.

Quintero M S, Georgopoulos A, Stylianidis E, Lerma J L \& Remondino F (2017). CIPA's Mission Digitally Documenting Cultural Heritage. APT Bulletin: The Journal of Preservation Technology, 48(4), 51-54. Retrieved from https://www-jstororg.i.ezproxy.nypl.org/stable/26382567

Sanz-Ablanedo E, Chandler J H, Rodríguez-Pérez J R \& Ordóñez C (2018). Accuracy of Unmanned Aerial Vehicle (UAV) and SfM Photogrammetry Survey as a Function of the Number and Location of Ground Control Points Used. Remote Sensing, 10(10), 1606. Retrieved from https://www.mdpi.com/20724292/10/10/1606

Schuhr W \& Kanngieser E (1999). Single images in conservation. Paper presented at the CIPA Task Group 2; CIPA Symposium Olinda, Brazil.

Schuhr W \& Kanngieser E (2003). New perspectives for single images in conservation. Paper presented at the CIPA Task Group 2; CIPA Symposium, Antalya, Turkey.

Shatnawi N \& Obaidat M T (2019). Extraction of AsBuilt Drawings Using Cell Phone Camera. Jordan Journal of Civil Engineering, 13(1), 21-29.

Stylianidis E (2020). Photogrammetric Survey for the Recording and Documentation of Historic Buildings. Switzerland: Springer.

Takahashi Y \& Chikatsu H (2009). Accuracy Aspects of Mobile Phone Cameras for Digital Close Range Photogrammetry. Journal of the Japan society of photogrammetry and remote sensing, 48(5), 299-307. doi:10.4287/jsprs.48.299 